Received: 12 December 2016

Accepted: 4 May 2017

Published online: 20 June 2017

\section{OPEN Impact of initial active engagement in self-monitoring with a telemonitoring device on glycemic control among patients with type 2 diabetes}

\begin{abstract}
Min-Kyung Lee ${ }^{1}$, Kwang-Hyeon Lee ${ }^{2}$, Seung-Hyun Yoo ${ }^{3}$ \& Cheol-Young Park $\mathbb{D}^{4}$
This study aimed to investigate the effect of patient engagement in self-monitoring with a telemonitoring device on glycemic control among patients with type 2 diabetes. We conducted a subanalysis of the telemonitoring device study in Kaiser Permanente Northern California members. We divided the telemonitoring group into 53 frequent and 54 infrequent users based on self-monitoring of blood glucose (SMBG) frequency of the first 6 weeks. The frequency of SMBG transmitted from the telemonitoring device was examined over 24 weeks. Clinic and laboratory tests were collected at baseline, 6 weeks and 6 months. There was no significant difference in baseline HbAlc level between the two groups. After 6 months, change in $\mathrm{HbA1c}$ was $-2.4 \pm 1.6 \%$ among frequent users and $-1.5 \pm 1.5 \%$ among infrequent users $(p=0.003)$. The proportion of patients achieving target $\mathrm{HbA1C}$ level at 6 months was significantly higher among frequent users than among infrequent users. An increased frequency of SMBG was significantly correlated with a reduction in HbA1c at 6 months. In conclusion, initial active engagement in self-monitoring with a telemonitoring device could provide incremental improvement of glycemic control over 6 months.
\end{abstract}

Diabetes mellitus is a chronic illness requiring continuous medical care ${ }^{1}$, and cases of uncontrolled diabetes or complications from diabetes are especially costly ${ }^{2}$. Glucose, blood pressure, and lipid control are important for preventing complications and reducing the cost associated with diabetes. Successful care of diabetes requires patient self-management, including adherence to medication, self-monitoring of glucose and blood pressure, and healthy lifestyle modifications ${ }^{3}$. Diabetes self-management is especially important among people with uncontrolled diabetes or with diabetes complications ${ }^{4}$. However, diabetes self-management is difficult to maintain, and ongoing education and support through frequent contact with diabetes care managers are needed ${ }^{5}$.

Telemonitoring systems have been introduced as a tool for managing type 2 diabetes mellitus ${ }^{6}$. In several clinical trials, telemonitoring interventions delivered via cellular phones and the internet have been shown to improve diabetes outcomes ${ }^{7,8}$ and reduce diabetes care costs in the management of this chronic disease ${ }^{9,10}$. However, health outcomes with telemonitoring systems among patients with diabetes have varied widely ${ }^{11}$, and a telemonitoring system alone is unlikely to improve outcomes ${ }^{12}$. Identifying the effectiveness of telemonitoring devices remains a challenge due to variability among patients' self-management abilities. Patient engagement in type 2 diabetes self-management could be an important mediator in the effectiveness of telemonitoring devices ${ }^{13}$.

The Kaiser Permanente Northern California (KPNC) Medical Center in Santa Rosa, California, USA, conducted a 6-month randomized clinical study to evaluate the effectiveness of the Samsung Health Diary (SHD, Seoul, Korea) telemonitoring device among Kaiser Permanente members with type 2 diabetes. This study reported

${ }^{1}$ Division of Endocrinology and Metabolism, Department of Internal Medicine, Myongji hospital, Seonam University College of Medicine, Gyeonggi-do, Korea. ${ }^{2}$ Samsung Electronics Co. Ltd., Service R\&D Team, Mobile Communications Business, Gyeonggi-do, Korea. ${ }^{3}$ National Health Insurance Service, Seoul, Korea. ${ }^{4}$ Division of Endocrinology and Metabolism, Department of Internal Medicine, Kangbuk Samsung Hospital, Sungkyunkwan University School of Medicine, Seoul, Korea. Correspondence and requests for materials should be addressed to C.-Y.P. (email: cydoctor@chol.com) 


\begin{tabular}{|c|c|c|c|c|c|}
\hline & \multirow[b]{2}{*}{$\begin{array}{l}\text { Standard care } \\
\text { group }(n=91)\end{array}$} & \multicolumn{3}{|c|}{ Telemonitoring group } & \multirow[b]{2}{*}{$\mathbf{p}$} \\
\hline & & $\begin{array}{l}\text { Infrequent users } \\
(n=54)\end{array}$ & $\begin{array}{l}\text { Frequent users } \\
(n=53)\end{array}$ & $\mathbf{p}^{*}$ & \\
\hline Age, yr & $56.4 \pm 8.7$ & $53.5 \pm 9.6$ & $55.8 \pm 9.9$ & 0.225 & 0.209 \\
\hline Sex, male, \% $(n)$ & $60.4(55)$ & $58.2(32)$ & $67.3(35)$ & 0.550 & 0.594 \\
\hline Weight, kg & $104.4 \pm 20.0$ & $104.2 \pm 20.8$ & $104.4 \pm 15.9$ & 0.949 & 0.996 \\
\hline BMI, $\mathrm{kg} / \mathrm{m}^{2}$ & $35.5 \pm 6$ & $35.5 \pm 6.5$ & $34.1 \pm 6.4$ & 0.264 & 0.408 \\
\hline SBP, mmHg & $127.3 \pm 17.1$ & $126.8 \pm 15.4$ & $129.0 \pm 16.1$ & 0.343 & 0.776 \\
\hline LDL-C, mg/dL & $88.4 \pm 31.6$ & $91.7 \pm 35.4$ & $90.6 \pm 37.5$ & 0.876 & 0.840 \\
\hline Fructosamine, $\mu \mathrm{mol} / \mathrm{L}$ & $324 \pm 73.2$ & $306.5 \pm 57.8$ & $324.8 \pm 76.8$ & 0.166 & 0.283 \\
\hline HbA1c, \% & $9.2 \pm 1.5$ & $9.4 \pm 1.4$ & $9.2 \pm 1.4$ & 0.461 & 0.602 \\
\hline Self-efficacy scale & $144.8 \pm 34.3^{\dagger}$ & $142.0 \pm 30.0^{\dagger}$ & $161.6 \pm 27.6$ & $<0.001^{*}$ & $0.002^{*}$ \\
\hline
\end{tabular}

Table 1. Baseline clinical characteristics among the groups. Data are expressed as the mean \pm SD. *p value between telemonitoring groups. ${ }^{\dagger}$ No differences between the groups with the same superscript symbol in posthoc analyses. ${ }^{\ddagger} \mathrm{p}<0.05$.

\begin{tabular}{|c|c|c|c|c|c|}
\hline & \multirow[t]{2}{*}{$\begin{array}{l}\text { Standard care } \\
\text { group }(n=91)\end{array}$} & \multicolumn{3}{|c|}{ Telemonitoring group } & \multirow[b]{2}{*}{ p } \\
\hline & & $\begin{array}{l}\text { Infrequent } \\
\text { users }(n=54)\end{array}$ & $\begin{array}{l}\text { Frequent users } \\
(n=53)\end{array}$ & $\mathbf{p}^{*}$ & \\
\hline \multicolumn{6}{|c|}{ After 6 weeks from baseline } \\
\hline Weight, kg & $-2.4 \pm 5.5$ & $-1.7 \pm 8.5$ & $-3.3 \pm 10.9$ & 0.398 & 0.539 \\
\hline BMI, $\mathrm{kg} / \mathrm{m}^{2}$ & $0.3 \pm 4$ & $0.2 \pm 4.5$ & $-0.1 \pm 1.8$ & 0.652 & 0.842 \\
\hline SBP, $\mathrm{mmHg}$ & $-3.2 \pm 4^{\dagger}$ & $-0.7 \pm 14.3^{\dagger}$ & $-6.5 \pm 13.9$ & $0.035^{\ddagger}$ & $0.021^{*}$ \\
\hline $\mathrm{LDL}-\mathrm{C}, \mathrm{mg} / \mathrm{dL}$ & $-2.4 \pm 20.4$ & $-10.9 \pm 76.1^{\dagger}$ & $-15.2 \pm 32.0^{\dagger}$ & 0.704 & $0.012^{*}$ \\
\hline Fructosamine, $\mu \mathrm{mol} / \mathrm{L}$ & $-59.4 \pm 63^{\dagger}$ & $-37.8 \pm 44.2$ & $-70.1 \pm 76.1^{\dagger}$ & $0.008^{*}$ & $0.023^{* *}$ \\
\hline \multicolumn{6}{|c|}{ After 6 months from baseline } \\
\hline Weight, kg & $-1.1 \pm 11.4$ & $0.3 \pm 10.6$ & $2.5 \pm 18.2$ & 0.445 & 0.516 \\
\hline BMI, $\mathrm{kg} / \mathrm{m}^{2}$ & $-0.02 \pm 1.2$ & $0.0 \pm 1.5$ & $-0.1 \pm 2.4$ & 0.796 & 0.914 \\
\hline $\mathrm{SBP}, \mathrm{mmHg}$ & $-1.1 \pm 16.8$ & $-0.3 \pm 16.1$ & $-2.5 \pm 17.9$ & 0.505 & 0.789 \\
\hline $\mathrm{LDL}-\mathrm{C}, \mathrm{mg} / \mathrm{dL}$ & $-5.4 \pm 28$ & $-9.1 \pm 32.8$ & $-12.8 \pm 35.5$ & 0.576 & 0.387 \\
\hline Fructosamine, $\mu \mathrm{mol} / \mathrm{L}$ & $-51 \pm 75$ & $-20.5 \pm 64.3$ & $-78.4 \pm 81.2$ & $<0.001^{*}$ & $<0.001^{\ddagger}$ \\
\hline HbAlc, \% & $-1.8 \pm 1.7^{\dagger}$ & $-1.5 \pm 1.5^{\dagger}$ & $-2.4 \pm 1.6$ & $0.003^{\ddagger}$ & $0.011^{*}$ \\
\hline Self-efficacy scale & $14.7 \pm 33.1$ & $10.6 \pm 35.1$ & $7.7 \pm 22.1$ & 0.611 & 0.417 \\
\hline
\end{tabular}

Table 2. Changes from baseline to 6 weeks and 6 months among the groups. Data are expressed as the mean $\pm \mathrm{SD}$. ${ }^{*} \mathrm{p}$ value between the telemonitoring group. ${ }^{\dagger}$ No differences between the groups with same superscript symbols in post-hoc analyses. ${ }^{*} \mathrm{p}<0.05$.

that the telemonitoring device did not demonstrate a beneficial effect on glycemic control ${ }^{14}$. We found that the frequency of telemonitoring varied among the participants. The frequency of self-monitoring of blood glucose (SMBG) transmitted from the telemonitoring device was tracked to assess patient engagement. We conducted a subanalysis to determine whether a telemonitoring device would be beneficial for patients engaging in more frequent SMBG. The objective of the study was to investigate the effect of initial engagement in self-monitoring with a telemonitoring device on glycemic control among patients with type 2 diabetes.

\section{Results}

Characteristics of the study population. The telemonitoring group was divided into 54 infrequent users and 53 frequent users based on the average SMBG frequency for the first 6 weeks. Table 1 shows the baseline characteristics of the standard care and infrequent and frequent user groups. There were no significant differences among the three groups in age, sex, weight, or body mass index (BMI) or in the outcome measures of systolic blood pressure (SBP), low-density lipoprotein cholesterol (LDL-C), fructosamine, or HbA1c levels. The mean $\mathrm{HbAlc}$ level was $9.2 \pm 1.4 \%(77 \pm 15 \mathrm{mmol} / \mathrm{mol})$ among frequent users and $9.4 \pm 1.4 \%(79 \pm 15 \mathrm{mmol} /$ $\mathrm{mol}$ ) among infrequent users, and there was no significant difference in HbAlc level between the two groups $(\mathrm{p}=0.461)$. The self-efficacy score was $161.6 \pm 27.6$ among frequent users, $142.0 \pm 30.0$ among infrequent users, and $144.8 \pm 34.3$ in the standard care group. The frequent users had significantly higher self-efficacy scores than did infrequent users $(\mathrm{p}<0.001)$.

Change from baseline to 6 weeks and 6 months in the telemonitoring group. Table 2 shows changes from baseline to 6 weeks and 6 months among the three groups. Frequent users showed the greatest improvement in SBP, LDL-C, and fructosamine levels at 6 weeks. At 6 months, HbA1C level improved significantly among frequent users relative to infrequent users and the standard care group, with mean changes 


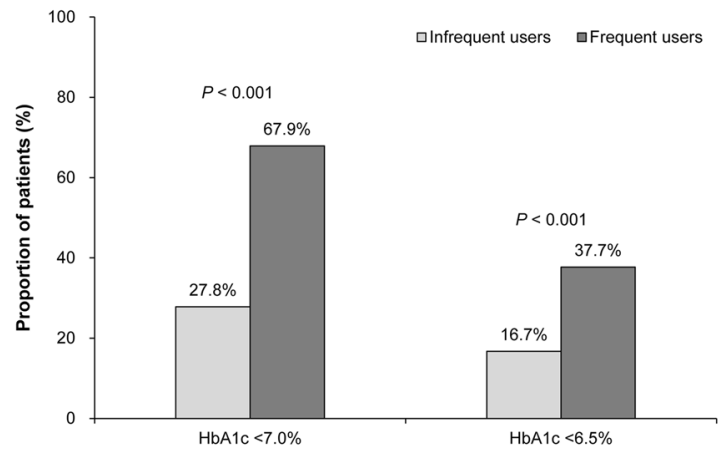

Figure 1. Proportion of patients achieving target $\mathrm{HbA} 1 \mathrm{C}$ at 6 months.

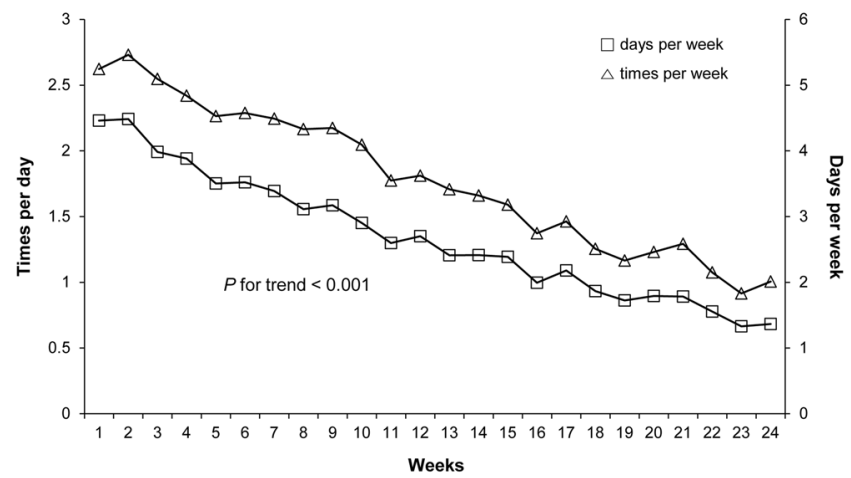

Figure 2. Frequency of weekly self-monitoring of blood glucose (SMBG) in the telemonitoring group. Data are expressed as mean \pm SEM.

in $\mathrm{HbA} 1 \mathrm{C}$ of $-2.4 \pm 1.6 \%(-26 \pm 17 \mathrm{mmol} / \mathrm{mol}),-1.5 \pm 1.5 \%(-16 \pm 16 \mathrm{mmol} / \mathrm{mol})$ and $-1.8 \pm 1.7 \%$ $(-20 \pm 18 \mathrm{mmol} / \mathrm{mol})$, respectively $(\mathrm{p}=0.011)$. Fructosamine, which reflects glycemic control for the previous 2 to 4 weeks ${ }^{15}$, was significantly reduced among frequent users compared with infrequent users after 6 weeks $(-70.1 \pm 76.1$ vs. $37.8 \pm 44.2 ; \mathrm{p}=0.008)$; this gap increased after 6 months $(-78.4 \pm 81.2 \mathrm{vs.}-20.5 \pm 64.3$; $\mathrm{p}<0.001)$. In addition, at 6 months, there were no significant differences in the changes in BMI, SBP, LDL-C, and self-efficacy scores between frequent and infrequent users. We compared the attainment of the HbA1C target goal at 6 months in the two telemonitoring groups (Fig. 1). The proportion of patients achieving target $\mathrm{HbA} 1 \mathrm{C}$ level at 6 months was significantly higher among frequent users than among infrequent users. The percentage of patients who achieved $\mathrm{HbAlc}<7.0 \%$ at 6 months was $27.8 \%$ among infrequent users and $67.9 \%$ among frequent users $(\mathrm{p}<0.001) ; 16.7 \%$ and $37.7 \%$ achieved HbA1c $<6.5 \%$, respectively $(\mathrm{p}<0.001)$.

Frequency of SMBG in the telemonitoring group. The telemonitoring participants performed SMBG an average of $1.99 \pm 0.66$ times per day for the first 6 weeks. Two participants (1.9\%) never transmitted any SMBG data during the 24-week follow-up period. Another 25 participants $(23.4 \%)$ performed SMBG on average $<1$ time per day, and only one participant $(0.1 \%)$ performed SMBG on average $>5$ times per day; the remaining 79 participants (73.8\%) performed SMBG between 1 and 4 times per day. The mean SMBG was testing $1.34 \pm 0.98$ times per day and $3.57 \pm 2.03$ days per week for 24 weeks. Figure 2 depicts the weekly SMBG frequencies in the telemonitoring group. SMBG frequency was $2.23 \pm 1.43$ times per day in the first week, $1.76 \pm 1.35$ at 6 weeks, and $0.68 \pm 1.12$ at 24 weeks. The fasting blood glucose level was $174.8 \pm 50.95 \mathrm{mg} / \mathrm{dl}$ in the first week, $157.8 \pm 49.13$ at 6 weeks, and $142.2 \pm 29.01$ at 24 weeks. The weekly SMBG frequency gradually decreased over 24 weeks (p for trend $<0.001)$, and this was in concordance with the result as fasting blood glucose levels were relatively stable ( $\mathrm{p}$ for trend $<0.001$ ).

Table 3 shows the frequency of SMBG every 6 weeks for 24 weeks among frequent and infrequent users. The frequency of SMBG over the first 6 weeks was $2.88 \pm 0.67$ times per day among frequent users and $1.09 \pm 0.65$ among infrequent users. SMBG frequencies were significantly higher among frequent users than among infrequent users throughout the 24 weeks of follow-up.

Association between SMBG frequency and glycemic control. In the telemonitoring group, the correlations between SMBG frequency and other variables (age, sex, weight, BMI, SBP, LDL-C, fructosamine, $\mathrm{HbA1c}$, and self-efficacy score at baseline) were examined. Linear regression analysis revealed that age $(\beta=0.024$; $\mathrm{p}=0.020)$ and baseline self-efficacy scores $(\beta=0.010 ; \mathrm{p}=0.005)$ were significantly associated with SMBG frequency of the first 6 weeks (supplementary Table S1). In multiple linear regression analysis, SMBG frequency was significantly associated with reduction in HbA1c level at 6 months (Table 4). Changes in HbA1c at 6 months 


\begin{tabular}{|l|l|l|l|l|l|l|}
\hline \multirow{3}{*}{$\begin{array}{l}\text { SMBG } \\
\text { frequency }\end{array}$} & \begin{tabular}{l} 
Times per day \\
\cline { 2 - 7 } \\
Infrequent
\end{tabular} & $\begin{array}{l}\text { Frequent } \\
\text { users }\end{array}$ & $\mathbf{p}$ & $\begin{array}{l}\text { Infrequent } \\
\text { users }\end{array}$ & $\begin{array}{l}\text { Frequent } \\
\text { users }\end{array}$ & p \\
\hline Total & $0.77 \pm 0.72$ & $1.92 \pm 0.86$ & $<0.001$ & $2.54 \pm 1.95$ & $4.7 \pm 1.48$ & $<0.001$ \\
\hline Week 1 to 6 & $1.09 \pm 0.65$ & $2.88 \pm 0.67$ & $<0.001$ & $3.53 \pm 2.15$ & $6.38 \pm 0.76$ & $<0.001$ \\
\hline Week 6 to 12 & $0.89 \pm 0.94$ & $2.09 \pm 1.03$ & $<0.001$ & $2.9 \pm 2.51$ & $5.25 \pm 1.96$ & $<0.001$ \\
\hline $\begin{array}{l}\text { Week 12 } \\
\text { to 18 }\end{array}$ & $0.64 \pm 0.94$ & $1.57 \pm 1.17$ & $<0.001$ & $2.04 \pm 2.42$ & $4.0 \pm 2.21$ & $<0.001$ \\
\hline $\begin{array}{l}\text { Week 18 } \\
\text { to 24 }\end{array}$ & $0.45 \pm 0.80$ & $1.15 \pm 1.14$ & $<0.001$ & $1.55 \pm 2.28$ & $2.91 \pm 2.40$ & $<0.001$ \\
\hline
\end{tabular}

Table 3. SMBG frequency between frequent users and infrequent users. Data are expressed as the mean $\pm \mathrm{SD}$.

\begin{tabular}{|c|c|c|c|c|c|c|c|c|}
\hline & \multicolumn{2}{|l|}{ Crude } & \multicolumn{2}{|l|}{ Model 1} & \multicolumn{2}{|l|}{ Model 2} & \multicolumn{2}{|l|}{ Model 3} \\
\hline & $\beta(95 \% \mathrm{CI})$ & $\mathbf{p}$ & $\beta(95 \% \mathrm{CI})$ & $\mathbf{p}$ & $\beta(95 \%$ CI $)$ & $\mathbf{p}$ & $\beta(95 \% \mathrm{CI})$ & $\mathbf{p}$ \\
\hline \multicolumn{9}{|c|}{ SMBG frequency (days per week) } \\
\hline Total & $\begin{array}{l}-0.444 \\
(-0.760--0.128)\end{array}$ & 0.006 & $\begin{array}{l}-0.502 \\
(-0.842--0.163)\end{array}$ & 0.004 & $\begin{array}{l}-0.522 \\
(-0.862--0.183)\end{array}$ & 0.003 & \begin{tabular}{|l|}
-0.676 \\
$(-0.933--0.420)$
\end{tabular} & $<0.001$ \\
\hline $\begin{array}{l}\text { Week } \\
1 \text { to } 6\end{array}$ & $\begin{array}{l}-0.458 \\
(-0.744--0.173)\end{array}$ & 0.002 & $\begin{array}{l}-0.492 \\
(-0.790--0.195)\end{array}$ & 0.001 & $\begin{array}{l}-0.626 \\
(-0.841--0.410)\end{array}$ & $<0.001$ & \begin{tabular}{|l|}
-0.444 \\
$(-0.889--0.442)$
\end{tabular} & $<0.001$ \\
\hline $\begin{array}{l}\text { Week } \\
6 \text { to } 24\end{array}$ & $\begin{array}{l}-0.311 \\
(-0.619--0.002)\end{array}$ & 0.048 & $\begin{array}{l}-0.364 \\
(-0.704--0.023)\end{array}$ & 0.037 & $\begin{array}{l}-0.493 \\
(-0.746--0.239)\end{array}$ & $<0.001$ & $\begin{array}{l}-0.498 \\
(-0.763--0.233)\end{array}$ & $<0.001$ \\
\hline \multicolumn{9}{|c|}{ SMBG frequency (days per week) } \\
\hline Total & $\begin{array}{l}-0.263 \\
(-0.410--0.116)\end{array}$ & 0.001 & $\begin{array}{l}-0.308 \\
(-0.463--0.153)\end{array}$ & $<0.001$ & $\begin{array}{l}-0.353 \\
(-0.464--0.241)\end{array}$ & $<0.001$ & $\begin{array}{l}-0.367 \\
(-0.485--0.249)\end{array}$ & $<0.001$ \\
\hline $\begin{array}{l}\text { Week } \\
1 \text { to } 6\end{array}$ & $\begin{array}{l}-0.263 \\
(-0.397--0.130)\end{array}$ & $<0.001$ & $\begin{array}{l}-0.295 \\
(-0.433--0.157)\end{array}$ & $<0.001$ & $\begin{array}{l}-0.330 \\
(-0.427--0.232)\end{array}$ & $<0.001$ & $\begin{array}{l}-0.352 \\
(-0.455--0.250)\end{array}$ & $<0.001$ \\
\hline $\begin{array}{l}\text { Week } \\
6 \text { to } 24\end{array}$ & $\begin{array}{l}-0.178 \\
(-0.314--0.041)\end{array}$ & 0.012 & $\begin{array}{l}-0.211 \\
(-0.358--0.064)\end{array}$ & 0.005 & $\begin{array}{l}-0.241 \\
(-0.352--0.130)\end{array}$ & $<0.001$ & $\begin{array}{l}-0.247 \\
(-0.365--0.129)\end{array}$ & $<0.001$ \\
\hline
\end{tabular}

Table 4. Association between change in $\mathrm{HbA1c}$ at 6 months and SMBG frequency in the telemonitoring group. Model 1 is adjusted for age and sex. Model 2 is adjusted for age, sex, and baseline self-efficacy scale. Model 3 is adjusted for age, sex, self-efficacy scale, BMI, SBP, LDL, and HbA1c at baseline.

were highly associated with the frequency of SMBG for the first 6 weeks. In multivariable analyses, after adjusting for age, sex, and baseline self-efficacy score (model 2), SMBG frequency was also significantly associated with changes in HbAlc. In model 3, after adjusting for age, sex, BMI, SBP, LDL-C, HbAlc, and self-efficacy score at baseline, the results were the same as with model 2 .

\section{Discussion}

This study evaluated the relationship between the frequency of SMBG based on data transmitted from a telemonitoring device and glycemic control. We found that an increased SMBG frequency for the first 6 weeks with the telemonitoring device was associated with improved glycemic control, as measured by HbAlc and fructosamine levels during the 6-month follow-up, among patients with type 2 diabetes. The telemonitoring device improved glycemic control early, late, and over the study period among frequent users who tested SMBG at least twice daily for the first 6 weeks. Initial active engagement in SMBG with a telemonitoring device was important in diabetes management.

This novel telemonitoring device was expected to provide an incremental benefit to diabetes management, but a previous study did not find that the telemonitoring device improved glycemic control above standard care ${ }^{14}$. The effects of telemonitoring systems can vary depending on patient engagement in diabetes self-management. In this study, we evaluated the effectiveness of a telemonitoring device when it was actively in use. We defined active users of the telemonitoring device based on the frequency of engaging in SMBG. A telemonitoring device could be a useful tool for improving the impact of self-monitoring by remotely linking patients with care manag$\mathrm{ers}^{16}$. It has also been reported that active care management provided via the telemonitoring device resulted in a significantly greater reduction in $\mathrm{HbAlc}_{\mathrm{c}}$ level ${ }^{17}$. The telemonitoring device does not cure patients with diabetes, but active use of a telemonitoring device can be a significant factor in improvement of diabetes management and glycemic control.

In the current study, a majority (73.8\%) of the telemonitoring group tested SMBG at least daily during the first 6 weeks, with an average of 1.99 times per day. This is much more frequent than what was observed in the National Health and Nutrition Examination Survey (NHANES) ${ }^{18}$. The frequency of SMBG gradually decreased in the telemonitoring group throughout the 24 weeks, but was consistently higher among frequent users than among infrequent users. SMBG is an integral component of diabetes therapy ${ }^{1}$, and structural SMBG is beneficial for patients with type 2 diabetes ${ }^{19}$; however, there is no guideline on the frequency of SMBG in non-insulin-treated type 2 diabetes ${ }^{20}$, and the added value of more frequent SMBG on glycemic control remains uncertain ${ }^{21}$. On the other hand, studies of insulin-treated type 1 diabetes have reported a correlation between SMBG frequency and 
glycemic control ${ }^{22,23}$. Similarly, our study of patients with type 2 diabetes also showed that greater SMBG frequency was significantly correlated with lower HbAlc level at 6 months.

All of the participants in our research received appropriate interventions within the context of a close relationship with their healthcare managers. The increased contact between patients and healthcare providers through telemonitoring interventions can lead to improvements in diabetes management ${ }^{24,25}$. Social support provided by healthcare workers can contribute to adherence among diabetic patients to such behaviors as following a diabetic diet, weight loss, taking prescribed medications, and checking blood glucose ${ }^{26}$. SMBG can be used to guide patients and healthcare providers in selecting appropriate pharmaceutical and lifestyle regimens to improve glycemic control on a day-to-day basis ${ }^{27}$. The previous study from the KPNC diabetes management also reported that patients initiating SMBG with a greater frequency had better glycemic control ${ }^{28}$. The current study indicated that SMBG frequency for the first 6 weeks could provide important feedback in order to improve long-term glycemic control among patients using the telemonitoring device.

We found that frequent SMBG during the initial engagement, not the whole study period, was associated with improved glycemic control. It will be difficult to sustain SMBG performance at least twice a day over a long period, due to patient compliance. We categorized frequent users as those who tested SMBG at least twice a day for the first 6 weeks, including measurement of fasting and postprandial glucose levels. However, our results cannot be a general guideline on the frequency of SMBG testing for type 2 diabetes patients. The current evidence suggests that SMBG frequency should be individualized depending on the clinical needs of individual patients and requirements of health providers ${ }^{20,29}$. Considering this, it would be difficult to carry out a randomized controlled trial in which the study participants were allocated to different fixed SMBG frequencies for a certain period. A larger multicenter prospective cohort study might be a reasonable alternative approach for investigating the optimal SMBG frequency for patients with type 2 diabetes.

A recent study reported that a telemonitoring system might be helpful for improving patient engagement in SMBG and health outcomes ${ }^{30}$. The current study did not evaluate whether the telemonitoring device could positively affect patient engagement in SMBG due to the lack of SMBG data in the standard care group. We found that the frequency of SMBG was correlated with age and baseline self-efficacy score. The diabetes self-efficacy scale was developed based on self-care activities ${ }^{31}$. The concept of self-efficacy is relevant for improving self-management because diabetes self-management incorporates behavioral, personal, and environmental factors into daily performance of recommended activities. Several studies have reported that self-efficacy score was associated with diabetes self-management including SMBG ${ }^{32-34}$. However, the current study demonstrated that SMBG frequency was significantly associated with reduction in HbA1c even after adjusting for self-efficacy score. On the other hand, the frequency of SMBG was not related to cardiovascular risk factors including LDL, SBP, and BMI. Frequent users were more likely to achieve greater reduction in SBP at 6 weeks, but this difference was not significant at 6 months.

This study has several limitations. First, this is a post-hoc analysis, and the data from the telemonitoring group was collected from a relatively small sample. Nevertheless, the study was adequately powered for the outcomes examined and produced statistically significant results. Second, we adjusted for confounding variables through multivariable analysis. However, we could not completely rule out other factors related to patient engagement such as diabetic education, diet, physical activities, and medications. Finally, the study had a small sample size and short-term follow-up period, so it is uncertain whether these results can be sustained over 6 months with or without KPNC diabetes management. To solve these problems, a larger prospective long-term study is needed.

The present study showed that an initial active engagement in self-monitoring with a telemonitoring device could predict improved glycemic control throughout 6 months of follow-up among patients with type 2 diabetes. Patient engagement with a telemonitoring device could be a significant factor contributing to diabetes management. Therefore, initial strategies to enhance patient engagement in self-monitoring with a telemonitoring device are critical, and further research is necessary to determine the optimal use of a telemonitoring device.

\section{Methods}

Study population and design. The study targeted Kaiser Permanente members with type 2 diabetes who visited the Santa Rosa (SRO) Diabetes Care Management Center from May 2009 to April 2011. If patients agreed to participate, informed consent was obtained. A total of 198 members with poor glycemic control (HbAlc $\geq 7.5 \%)$ were randomly assigned to a standard care group $(n=91)$ or a telemonitoring group $(n=107)$. The telemonitoring group used the Samsung Health Diary (SHD, Seoul, Korea) telemonitoring device at home to transmit blood glucose, blood pressure, and weight measurements to a diabetes care manager. Diabetes care managers also used the telemonitoring device to deliver appropriate educational informational messages. In contrast, the standard care group received information from their care managers via e-mail, fax, and telephone. Participants in both groups received telephone consultations under the KPNC diabetes management program. Identification and recruitment of patients have been described in a previous study ${ }^{14}$.

We conducted a subanalysis of SMBG data from the telemonitoring group over 24 weeks; SMBG data from the standard care group was not available for the current study. We divided the telemonitoring group into infrequent users and frequent users based on average SMBG frequency for the first 6 weeks. Frequent users tested at least twice daily for the first 6 weeks. All participants visited the medical center for baseline randomization, followed by 6-week and 6-month follow-up clinic or laboratory tests and a self-administered self-efficacy questionnaire.

The Kaiser Permanente Northern California (KPNC) diabetes program. KPNC Medical Center in Santa Rosa provided a traditional diabetes management program ${ }^{14}$. Both the standard care and telemonitoring groups received telephone consultations under this program. The 6-month care management program included an initial in-person office visit, followed by bi-weekly telephone calls. The major interventions were insulin self-titration, medication changes, and behavioral interventions. Medications were titrated for target goals based 
on data on patient glucose level sent to the medical center. Behavioral protocols included psycho/social referrals, diet, physical activity, smoking cessation, and others. Diabetes care managers provided appropriate interventions based on previously described target goals. Certified diabetes nurse educators, under the supervision of local endocrinologists and primary care physicians, were trained to use standard diabetes management protocols.

Samsung Health Diary (SHD, Seoul, Korea) telemonitoring device. The Samsung Health Diary (SHD, Seoul, Korea) functions as a home-based gateway for obtaining measurement data, such as blood glucose, blood pressure, and weight, and records information to a server through an internet connection. The SHD transmits patient data to care managers; blood glucose and blood pressure are transmitted using a serial cable, whereas weight measurements are transmitted wirelessly. Diabetes care managers also use the telemonitoring device to deliver appropriate educational information to patients. In this study, the telemonitoring group received information automatically through the telemonitoring device as well as through web portal care.

Outcomes. We evaluated the relationship between glycemic control and frequency of SMBG from the telemonitoring device to determine the utility of the SHD device among patients with type 2 diabetes. The primary outcome was to investigate whether increased SMBG for the first 6 weeks reduces HbA1C level at 6 months in both groups. The secondary outcome was to compare average fructosamine, weight, blood pressure, and LDL cholesterol measured at baseline, 6 weeks, and 6 months in all participants.

Statistical analysis. All data were analyzed using IBM SPSS version 18.0 (IBM, Armonk, NY, USA) and were presented as mean \pm standard deviation. We divided telemonitoring participants into frequent users and infrequent users according to frequency of SMBG and compared them to patients receiving standard care. The descriptive characteristics of the three groups were compared using either one-way analysis of variance (ANOVA) or t-tests for continuous variables, chi-square tests for categorical variables, and post hoc analyses with Tukey's $\mathrm{b}$ method. The study outcomes were calculated as follow-up minus baseline values. Repeated-measures ANOVA was used to monitor how the frequency of SMBG changed over 24 weeks. Data is presented as mean \pm standard error of mean. The frequency of SMBG in frequent users and infrequent users was compared using a t-test and was adjusted using the Bonferroni correction to reduce the chances of obtaining false-positive results (type I errors). Pearson's correlation analysis was used to explore the correlations between SMBG frequency and other variables. Univariate and multivariate linear regression analyses were used to explore the association between change in HbAlc level and SMBG frequency.

This project was approved by the Kaiser Foundation Research Institute's institutional review board. All methods were performed in accordance with the relevant guidelines and regulations.

Clinical trial registration number is NCT01775878, and the date of registration is January 23, 2013.

\section{References}

1. American Diabetes Association. Standards of medical care for patients with diabetes mellitus. Diabetes Care 26, S33-S50 (2003).

2. Williams, R., Van Gaal, L. \& Lucioni, C. Assessing the impact of complications on the costs of Type II diabetes. Diabetologia 45 , S13-S17 (2002).

3. Haas, L. et al. National standards for diabetes self-management education and support. Diabetes Care 37(Suppl 1), S144-S153 (2014).

4. Norris, S. L., Engelgau, M. M. \& Narayan, K. M. Effectiveness of self-management training in type 2 diabetes: a systematic review of randomized controlled trials. Diabetes Care 24, 561-587 (2001).

5. Brown, S. A. Interventions to promote diabetes self-management: state of the science. The Diabetes educator 25, 52-61 (1999).

6. Bellazzi, R. Telemedicine and diabetes management: current challenges and future research directions. Journal of diabetes science and technology 2, 98-104 (2008).

7. Farmer, A., Gibson, O. J., Tarassenko, L. \& Neil, A. A systematic review of telemedicine interventions to support blood glucose selfmonitoring in diabetes. Diabetic medicine: a journal of the British Diabetic Association 22, 1372-1378 (2005).

8. Health Quality Ontario. Home telemonitoring for type 2 diabetes: an evidence-based analysis. Ontario health technology assessment series 9, 1-38 (2009).

9. Pare, G., Poba-Nzaou, P. \& Sicotte, C. Home telemonitoring for chronic disease management: an economic assessment. International journal of technology assessment in health care 29, 155-161 (2013).

10. Yoo, H. J. et al. A Ubiquitous Chronic Disease Care system using cellular phones and the internet. Diabetic medicine: a journal of the British Diabetic Association 26, 628-635 (2009).

11. Mushcab, H., Kernohan, W. G., Wallace, J. \& Martin, S. Web-Based Remote Monitoring Systems for Self-Managing Type 2 Diabetes: A Systematic Review. Diabetes technology \& therapeutics 17, 498-509 (2015).

12. Wakefield, B. J. et al. Effect of home telemonitoring on glycemic and blood pressure control in primary care clinic patients with diabetes. Telemedicine journal and e-health: the official journal of the American Telemedicine Association 20, 199-205 (2014).

13. Graffigna, G., Barello, S., Bonanomi, A. \& Menichetti, J. The Motivating Function of Healthcare Professional in eHealth and mHealth Interventions for Type 2 Diabetes Patients and the Mediating Role of Patient Engagement. Journal of diabetes research 2016, 2974521 (2016).

14. Pressman, A. R. et al. A novel telemonitoring device for improving diabetes control: protocol and results from a randomized clinical trial. Telemedicine journal and e-health: the official journal of the American Telemedicine Association 20, 109-114 (2014).

15. Armbruster, D. A. Fructosamine: structure, analysis, and clinical usefulness. Clinical chemistry 33, 2153-2163 (1987).

16. Currell, R., Urquhart, C., Wainwright, P. \& Lewis, R. Telemedicine versus face to face patient care: effects on professional practice and health care outcomes. The Cochrane database of systematic reviews 2, Cd002098 (2000).

17. Stone, R. A. et al. Active care management supported by home telemonitoring in veterans with type 2 diabetes: the DiaTel randomized controlled trial. Diabetes Care 33, 478-484 (2010).

18. Sarol, J. N. Jr., Nicodemus, N. A. Jr., Tan, K. M. \& Grava, M. B. Self-monitoring of blood glucose as part of a multi-component therapy among non-insulin requiring type 2 diabetes patients: a meta-analysis (1966-2004). Current medical research and opinion 21, 173-184(2005).

19. Davidson, M. B. Self-monitoring of blood glucose in patients with type 2 diabetes who are not using insulin: response to Welschen et al. and Kleefstra et al. Diabetes Care 28, 2597; author reply 2597-2598 (2005). 
20. International Diabetes Federation. IDF Guideline on Self-Monitoring of Blood Glucose in Non-Insuling Treated Type 2 Diabetes (International Diabetes Federation: Brussels, 2009).

21. Allemann, S., Houriet, C., Diem, P. \& Stettler, C. Self-monitoring of blood glucose in non-insulin treated patients with type 2 diabetes: a systematic review and meta-analysis. Current medical research and opinion 25, 2903-2913 (2009).

22. Miller, K. M. et al. Evidence of a strong association between frequency of self-monitoring of blood glucose and hemoglobin Alc levels in T1D exchange clinic registry participants. Diabetes Care 36, 2009-2014 (2013).

23. Harris, M. I. Frequency of blood glucose monitoring in relation to glycemic control in patients with type 2 diabetes. Diabetes Care 24, 979-982 (2001).

24. Wasson, J. et al. Telephone care as a substitute for routine clinic follow-up. Jama 267, 1788-1793 (1992).

25. Kim, H. S., Cho, J. H. \& Yoon, K. H. New Directions in Chronic Disease Management. Endocrinology and metabolism (Seoul, Korea) 30, 159-166 (2015).

26. Sherbourne, C. D., Hays, R. D., Ordway, L., DiMatteo, M. R. \& Kravitz, R. L. Antecedents of adherence to medical recommendations: results from the Medical Outcomes Study. Journal of behavioral medicine 15, 447-468 (1992).

27. Renard, E. Monitoring glycemic control: the importance of self-monitoring of blood glucose. The American journal of medicine 118, S12-S19 (2005).

28. Karter, A. J. et al. Longitudinal study of new and prevalent use of self-monitoring of blood glucose. Diabetes Care 29, 1757-1763 (2006).

29. Standards of Medical Care in Diabetes-2016 Abridged for Primary Care Providers. Clinical diabetes: a publication of the American Diabetes Association 34, 3-21 (2016)

30. Kim, J. M., Lee, H. J., Kim, K. O., Won, J. C. \& Ko, K. S. Clinical Evaluation of OneTouch Diabetes Management Software System in Patients with Type 2 Diabetes Mellitus. Diabetes Metab J 40, 129-139 (2016)

31. Bijl, J. V., Poelgeest-Eeltink, A. V. \& Shortridge-Baggett, L. The psychometric properties of the diabetes management self-efficacy scale for patients with type 2 diabetes mellitus. Journal of advanced nursing 30, 352-359 (1999).

32. Al-Khawaldeh, O. A., Al-Hassan, M. A. \& Froelicher, E. S. Self-efficacy, self-management, and glycemic control in adults with type 2 diabetes mellitus. Journal of diabetes and its complications 26, 10-16 (2012).

33. Gao, J. et al. Effects of self-care, self-efficacy, social support on glycemic control in adults with type 2 diabetes. BMC family practice 14, 66 (2013).

34. Sarkar, U., Fisher, L. \& Schillinger, D. Is self-efficacy associated with diabetes self-management across race/ethnicity and health literacy? Diabetes Care 29, 823-829 (2006).

\section{Acknowledgements}

The authors express our appreciation to Alice R. Pressman and Jerome Minkoff who performed the clinical trial at Kaiser Permanente Northern California (KPNC) Medical Center. We would like to thank Jeong-Je Park for his assistance with data collection.

\section{Author Contributions}

M.K.L. and C.Y.P. contributed to study design and data analysis. M.K.L. collected and organized data, wrote, reviewed, and edited the manuscript. C.Y.P. provided supervision and revised the manuscript. K.H.L. provided technical support for the study. M.K.L., S.H.Y., and C.Y.P. participated in the analytical discussion of the results. All authors read and approved the final manuscript.

\section{Additional Information}

Supplementary information accompanies this paper at doi:10.1038/s41598-017-03842-2

Competing Interests: K.H.L. was employed by ${ }^{2}$ Samsung Electronics Co. Ltd., Health R\&D Group.

Publisher's note: Springer Nature remains neutral with regard to jurisdictional claims in published maps and institutional affiliations.

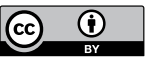

Open Access This article is licensed under a Creative Commons Attribution 4.0 International License, which permits use, sharing, adaptation, distribution and reproduction in any medium or format, as long as you give appropriate credit to the original author(s) and the source, provide a link to the Creative Commons license, and indicate if changes were made. The images or other third party material in this article are included in the article's Creative Commons license, unless indicated otherwise in a credit line to the material. If material is not included in the article's Creative Commons license and your intended use is not permitted by statutory regulation or exceeds the permitted use, you will need to obtain permission directly from the copyright holder. To view a copy of this license, visit http://creativecommons.org/licenses/by/4.0/.

(C) The Author(s) 2017 